\title{
Changes in forest landscape patterns resulting from recent afforestation in Europe (1990-2012): defragmentation of pre-existing forest versus new patch proliferation
}

\author{
Marina Palmero-Iniesta ${ }^{1} \cdot$ Josep Maria Espelta ${ }^{1,2} \cdot$ Javier Gordillo $^{1} \cdot$ Joan Pino ${ }^{1,2}$ \\ Received: 19 November 2019 / Accepted: 16 March 2020 / Published online: 21 April 2020 \\ (C) INRAE and Springer-Verlag France SAS, part of Springer Nature 2020
}

\begin{abstract}
- Key message Recent afforestation in Europe might involve deep changes on landscape composition and configuration. We show that afforestation promotes defragmentation of pre-existing forests and new patch proliferation, in forestdominated and non-forest-dominated landscapes respectively, while it is not associated to decreasing landscape diversity. These processes are modulated by geographic factors and might affect functional connectivity and biodiversity conservation in newly forested landscapes.

- Context A recent forest increase in Europe might drive changes in the landscape pattern, with increasing forest defragmentation and connectivity but decreasing land cover diversity that, in turn, might affect biodiversity conservation. However, little is known about these patterns of change and their association with the environmental context.

- Aims To explore the association of forest cover increase with changes in the spatial pattern of European landscapes, while considering their original landscape composition, geographical position and elevation.

- Methods We obtained data from ESA and GFC land cover maps and other GIS layers and performed a set of GLM on randomly selected 752 landscapes with recent (1990-2012) forest increase.

- Results A decrease in landscape diversity in the last decades was not associated to forest increase but to high cropland and low scrub-grassland cover. A forest increase promoted the defragmentation of already-existing forests and new patch proliferation in forest-dominated and non-dominated landscapes, respectively. These processes also depend on elevation and geographical position, with forest defragmentation concentrated in Northern and Eastern Europe and new patch proliferation in southern and western regions, and in mid-elevation areas.

- Conclusion Changes in afforested landscapes are more complex than expected and cannot be solely attributable to forest increase, but also to landscape composition and location across elevation and geographical gradients across Europe.
\end{abstract}

Handling Editor: Arndt Hampe

Contribution of the co-authors M.P.-I., J.M.E. and J.P. conceived and designed the research. M.P.-I. and J.G. acquired and processed the data. M.P.-I. performed the statistical analyses and J.P. assisted with the analyses. M.P.-I., J.M.E. and J.P. were involved in writing, revising and editing the manuscript.

This article is part of the topical collection on Establishment of secondgrowth forests in human landscapes: ecological mechanisms and genetic consequences

\footnotetext{
Marina Palmero-Iniesta

m.palmero@creaf.uab.cat

Josep Maria Espelta

Josep.Espelta@uab.cat

Javier Gordillo

j.gordillo@creaf.uab.cat
}

Joan Pino

Joan.Pino@uab.cat

CREAF, E08193, Bellaterra, Cerdanyola del Vallès, Spain

2 Universitat Autònoma de Barcelona, E08193, Bellaterra, Cerdanyola del Vallès, Spain 
Keywords Forest transition $\cdot$ Forest spatial pattern $\cdot$ Land cover change $\cdot$ Landscape diversity $\cdot$ Landscape metrics

\section{Introduction}

Deforestation is a primary land-use change on a world scale (Pagnutti et al. 2013), yet the overall decline in forest cover has fallen in recent decades due to forest transition (Meyfroidt and Lambin 2011), which has determined a change from net deforestation to net reforestation at both national and regional scales particularly in the northern hemisphere (Rudel et al. 2009). Indeed, forest transition has been taking place in many European and North American regions since the beginning of the twentieth century (Rudel et al. 2005) and, more recently, in the northern Mediterranean Basin (Mazzoleni et al. 2004). Gerard et al. (2010) detected an overall increase in forest cover in Europe in the second half of the twentieth century using land cover maps for a specific set of landscape samples. Recent works have highlighted that forest transition continues nowadays in Europe, with a net gain of $1.4 \%$ of forest surface between 1992 and 2015 detected from the European Space Agency global land cover maps (M. Palmero-Iniesta, unpublished results).

It is largely known that forest cover increase is affecting biodiversity conservation in Europe, with a generalized recovery of forest organisms including threatened species targeted in conservation initiatives (Plieninger et al. 2013; EEA 2016a). However, it also promotes a rarefaction and local extinction of species living in open habitats, including butterflies, birds and plants (Plieninger et al. 2013; Melero et al. 2016; Regos et al. 2016). In contrast, the effects of forest expansion on changes in the spatial pattern of the European landscapes are mostly unknown. In a seminal review on habitat loss and fragmentation (i.e. the reverse process to that analysed here), Fahrig (2003) observed a primary effect of habitat loss on biodiversity conservation, while the effects of habitat fragmentation per se (i.e. changes in habitat configuration but not in habitat cover) were much weaker and both positive and negative (see also Fahrig 2017). This would disagree with other works showing the importance of forest spatial pattern in the conservation of biodiversity and ecosystem functions, especially in highly transformed landscapes (e.g. Guirado et al. 2007; Ramage et al. 2013) where local disturbance regimes favour the extinction of forest specialists and the colonization by non-forest ones (Vellend et al. 2007; Basnou et al. 2015). As most of these works have been performed at local and regional scales, specific socio-environmental context might largely determine the effects of landscape configuration on biodiversity. Once again, little is known about the influence of this context on the changes in the spatial pattern following forest recovery in Europe, which is the previous essential step for understanding the effects of these changes on biodiversity.

The present work is aimed at addressing the association between forest cover increase and spatial pattern change in the
European landscapes, while considering the landscape land cover composition and the altitudinal and geographical gradients. The study takes profit of a recent set of medium- to highresolution land use and cover (LC) maps worldwide available: those of the Climate Change Initiative (CCI), which are derived from ENVISAT, POES and SPOT images by the European Spatial Agency (ESA 2017), and the forest cover change maps of the Global Land Cover Facility (GLCF) from the University of Maryland, which are derived from Landsat images (Hansen et al. 2013; Kim et al. 2014). Changes in landscape and in forest spatial pattern have been addressed through a set of classical landscape metrics regarding land cover diversity and habitat fragmentation and connectivity. We hypothesized that forest increase is determining (i) a decrease in the overall landscape diversity, (ii) a forest defragmentation and (iii) an increase in forest connectivity across Europe. Yet, these effects might depend on the initial forest cover if the association between forest cover increase and landscape change is not linear as observed by Fahrig (2003) in the reverse case of habitat fragmentation. Still, the geographical position determining climatic conditions responsible for differential forest recovery may modulate these landscape changes.

\section{Materials and methods}

\subsection{Study area}

The study was performed in Europe as the region bordered by the Arctic Ocean to the north, the Atlantic Ocean to the west, the Mediterranean Sea to the south and the Ural Mountains and the Caspian Sea to the east, and including the natural region of the Caucasus and the Anatolian Peninsula (Palmero et al. 2020). It comprises around $10^{7} \mathrm{~km}^{2}$ from 30 to $80^{\circ}$ of latitude and -30 to $70^{\circ}$ of longitude in the north hemisphere. Latitudinal and longitudinal climatic gradients and orography determine strong climatic variety in Europe (EEA 2016b). The relief of Europe is dominantly flat $(66 \%$ of the territory is below $200 \mathrm{~m}$ a.s.1.) although the influence of the mountains gives the territory a high ecological heterogeneity (IGN 2019). The current European landscape is the outcome of a long history of human land-use changes (Perlin and Journey 1989) in which forests and other wooded land now constitute the largest land cover type, extending over more than $43 \%$ of its area (EEA 2016b).

\subsection{Data sets on forest change and landscape composition}

Forest cover and its spatial pattern in 1990 and 2012 were derived from the GLCF datasets (Hansen et al. 2013; Kim et al. 
2014) covering all Europe, but only including forests. We used the oldest dataset available (1990-2000; www.landcover.com) to obtain a 1990 forest cover map with three categories: (i) forest, which included those pixels with already-existing forest and forest lost between 1990 and 2000; (ii) non-forest, which included the non-forest and the forests gained between the same period; and (iii) noise, which included shadow, clouds and no data pixels in the GLCF 1990-2000 that were excluded in later steps. A similar forest cover map was obtained for 2012 (http:// earthenginepartners.appspot.com/science-2013-global-forest/ download_v1.4.html), the most recent one in the GLCF datasets by categorizing the pixels of already-existing forest and of forest gain between 2000 and 2012 as forest, and the rest as non-forest. We also assessed the overall landscape composition through the land cover maps annually produced within the Climate Change Initiative of the European Spatial Agency (ESA CCI-LC), which are the complete land cover maps with the highest spatial resolution (300 m of pixel size) covering the whole of Europe (Diogo and Koomen 2016). We selected 1992 and 2012 land cover maps for the present study. The original CCI-LC land cover categories were reclassified into those proposed by the Intergovernmental Panel on Climate Change (IPCC; Eggleston et al. 2006), using the correspondence tables of the CCI-LC Product (see Table 3 in Appendix 1; ESA 2017).

\subsection{Sampling design and landscape metrics}

To assess changes in forest spatial pattern and in landscape composition due to forest increase, we randomly selected 2000 circular landscapes of 5-km radius across the study area. As the original GFC 1990-2000 had some noise (e.g. clouds, shadows), we discarded those landscapes with any type of noise (a total of 667 points) to avoid misinterpreting changes. Then, we calculated forest cover area (ha) in 1990 and 2012 for the remaining landscapes and we selected those with a positive forest increase between these dates $(n=752)$.

Changes in forest spatial pattern between the study dates were assessed from the 30-m-pixel-sized binary (forest/non-forest) maps mentioned above, through a set of landscape metrics aimed at describing forest fragmentation and forest connectivity (McGarigal and Marks 1994; Kupfer 2012). Their selection was based on (1) comparability with previous landscape ecological studies (ex. Turner 2005; Weng 2007) and (2) appropriateness for indicating ecological conditions (Debinski and Holt 2005; Kupfer 2012) and (3) for describing contrasting dimensions of the selected landscape attributes (McGarigal and Marks 1994; Fahrig 2003). Patch number and both mean and largest patch sizes were chosen as metrics of forest fragmentation. Moreover, patch size is known to be related to species richness and abundance (Boulinier et al. 2001; Debinski and Holt 2005). The total forest edge was also selected as a proxy of relevant fragmentation effects related to habitat alteration (Saunders et al. 1999). We finally selected effective mesh size (ha) for its high sensitivity to contrasting fragmentation processes (Jaeger 2000). Regarding forest connectivity, we selected the percentage of like adjacencies, which measures the degree of aggregation of patch types, and the Euclidean nearest neighbour distance, which measures the distance among patches of the same type and deals explicitly with the degree to which patches are spatially isolated from each other (McGarigal and Marks 1994).

On the other hand, to assess changes in land cover diversity, we calculated the Shannon diversity index for 1992 and 2012 for each study landscape using the CCI-LC map (300 m of pixel size). Landscape diversity is considered a key attribute of landscapes, indicative of its ability to house a variety of organisms and habitats (Turner 1989).

All these metrics were calculated for the selected study dates and study landscapes, using the datasets mentioned above and the R 'landscapemetrics' package (Hesselbarth et al. 2019).

\subsection{Environmental covariates}

In order to assess the modulating role of environmental context on the association between forest increase and landscape change, we included a set of variables regarding geographical position, topography and initial composition of the study landscapes in the study following the related literature (Heilman et al. 2002; Geri et al. 2010; Fernandes et al. 2011; Nagendra et al. 2013). The geographical position of landscapes is a proxy of their position along the observed climatic and socio-environmental gradients across Europe (Jongman 2002; Metzger et al. 2005), and it was described from the geographic coordinates of the landscape central point (latitude and longitude in UTM coordinates). Topography included mean elevation, obtained from the Global 30 Arc-Second Elevation (GTOPO30) dataset provided by the USGS (http://edcwww.cr.usgs.gov/landdaac/gtopo30/ gtopo30.html). The initial composition of landscapes (i.e. percentage of each land cover category) was inferred from the CCI-LC map of 1992. We calculated the cover percentage of the dominant land cover categories, namely forest and cropland (mean cover and standard error $39.02 \pm 1.27 \%$ and $37.34 \pm 1$. $31 \%$, respectively; see Table 3, Appendix 1). We then summed the cover of grasslands, wetlands, shrublands and sparse vegetation into a shrub/grassland category, noticeably represented in the study landscapes $(10.94 \pm 0.65 \%)$. We did not include the agroforestry mosaics, as this category is an undefined mixture of forest, scrubland, grassland and croplands, although it has relevance in the study landscapes $(9.32 \pm 0.54 \%)$.

\subsection{Statistical analyses}

In order to test if these landscape metrics differed between 1990 and 2012 (1992 and 2012 for the Shannon diversity index), we performed eight non-parametric Wilcoxon signed rank tests for paired samples for each landscape metric, after confirming the non-normal distribution of these metrics through the 
Kolmogorov-Smirnov test with Lilliefors modification. The significance of these tests was also adjusted with Bonferroni correction.

We performed eight general lineal models — one for each landscape metric - to test the association of changes in landscape metrics with forest increase, the environmental variables mentioned above and the interaction between both. To avoid multicollinearity, we firstly generated a correlation matrix with a Spearman rank and chose those less correlated variables $(r$ $<|0.7|$ ) (Table 4, Appendix 1). So, explanatory variables finally used on the linear models were forest increase (ha), forest cover $(\%)$, cropland cover $(\%)$, shrub/grassland cover $(\%)$, elevation $(\mathrm{m})$, latitude and longitude (degree) and the second-order interactions among the forest increase and the remaining variables. These interactions were included as we were particularly interested in exploring if the association between forest increase and landscape metrics varied according to environmental factors.

The simplest general lineal models were selected following a dredge procedure using MuMIn R package (Barton and Barton 2019), which removed non-significant variables from the general model, and assessed significant changes in model predictions using the Akaike information criterion (AIC). From the models with a difference in AIC relative to $\mathrm{AICmin}<2$, we chose the most parsimonious model by selecting the model with fewest predictor variables following the procedure described in Crawley (2007) (see Table 5, Appendix 1). In addition, we carefully considered all plausible models in order to not leave out an important explanatory variable by exploring model averaging based on an information criterion (see Table 6, Appendix 1). Moreover, null models were also performed for each landscape metric to investigate whether an observed pattern could have arisen by chance producing a type I error (Gotelli and Graves 1996). All the analyses were carried out with software R 2.15.0 (R Core Team 2012).

\section{Results}

On average, a significant increase in the size of both the largest and the mean forest patch and in the forest effective mesh size was observed in the studied landscapes (Table 1). Forest total edge and the number of forest patches also significantly increased as the Euclidean nearest neighbour distance did (Table 1). In contrast, the Shannon diversity index significantly decreased in the same landscapes. Our analyses failed to detect any significant change on the percentage of forest like adjacencies during the study period.

The best adequate model for each of the eight landscape metric variables included the effects of the environmental factors specified in Table 2. There were 5 to 10 other plausible models for each metric (difference in AIC in relation to AICmin <2) that varied in the presence of lower relative importance variables but always included the effects of all the selected variables in the selected model (see model averaging results in Table 5 and Table 6, Appendix 1). As shown in Table 2, explanatory variables accounted for a substantial proportion of total variability for some landscape metrics, as the increase in forest largest patch size and forest effective mesh size, but not for others (increase in forest mean patch size or Euclidean nearest neighbour distance). Selected models suggest that forest increase during the study period was not significantly associated with the increase in all the studied metrics (Table 2). It was positively associated with the increase in forest largest patch size, effective mesh size, total edge and the number of forest patches while the test failed to detect any significant association with the increase in the Shannon diversity index and in the percentage of like adjacencies.

Several environmental context variables were also significantly associated with the increase in the studied landscape metrics, sometimes through significant interactions with forest increase (Table 2). Initial forest cover showed a significant interaction with forest increase in both forest largest patch and effective mesh size, as these metrics increase more rapidly with forest increase in forest-dominated landscapes than in the rest (Fig. 3a, b; Appendix 2). There was also a significant interaction between initial forest cover and forest increase in both forest total edge and the number of forest patches, but in this case, the increase in these metrics with forest increase was lower in forest-dominated landscapes than in the rest (Fig. 3c, d; Appendix 2). Figure 1 illustrates the different new forest distribution pattern in forest-dominated landscapes, where new forest grew coalescent to the pre-existing forest, and in non-forestdominated landscapes, where forest grew in isolated patches.

Initial cropland cover showed a negative association with the number of forest patches and positive with the Shannon diversity index and the percentage of like adjacencies. It also showed a significant interaction with the increase in forest cover on that in some metrics. Thus, the increase in the percentage of like adjacencies following that in forest cover was higher in cropland-dominated landscapes than in the rest (Fig. 3e, Appendix 2). Shrub/grassland cover showed a negative association with the increase in both the number of forest patches and the Shannon diversity index and positive with that in the percentage of like adjacencies.

Besides, longitude and latitude showed a significant association with the increase in most of the metrics and some significant interactions with forest increase, and different patterns of forest growth were observed throughout Europe (Table 2, Fig. 2). Longitude showed a positive association with the increase in both the effective mesh size and the percentage of like adjacencies, and negative with the increase in forest total edge and in the number of forest patches. Latitude showed a positive association with the increase in both forest total edge and the Shannon diversity index, and negative with that in forest effective mesh size and in the percentage of like 
Table 1 Changes in the studied metrics in our study landscapes between 1990 and 2012 .

Wilcoxon test (paired samples) used to test significant

differences. Significant codes:

$\because>0.05,{ }^{\prime}{ }^{*} ’=0.05,{ }^{\prime} * * '=0.01$, '***' $=0.001$

\begin{tabular}{llllll}
\hline & Mean 1990 (SE) & Mean 2012 (SE) & $V$ value & $p$ value & Sign. \\
\hline Forest largest patch size (ha) & $1490(76.75)$ & $1860(88.87)$ & 29,816 & $<0.0001$ & $* * *$ \\
Forest mean patch size (ha) & $36.6(2.84)$ & $46.4(6.92)$ & 205,050 & $<0.0001$ & $* * *$ \\
Forest total edge (m) & $190,000(6764.11)$ & $257,000(8611.18)$ & 32,186 & $<0.0001$ & $* * *$ \\
Forest effective mesh size (ha) & $819(56.34)$ & $1140(71.19)$ & 26,197 & $<0.0001$ & $* * *$ \\
Number of forest patches & $56.4(2.04)$ & $129(4.56)$ & 18,583 & $<0.0001$ & $* * *$ \\
$\begin{array}{l}\text { Euclidean nearest neighbour } \\
\text { distance (m) }\end{array}$ & $152(9.47)$ & $131(4.41)$ & 94,471 & 0.046 & $*$ \\
$\begin{array}{l}\text { Percentage of forest like } \\
\text { adjacencies (\%) }\end{array}$ & $67.8(1.31)$ & $72.3(0.97)$ & 125,796 & 0.276 &. \\
\begin{tabular}{l} 
Shannon diversity index \\
\hline
\end{tabular} & $0.738(0.02)$ & $0.620(0.02)$ & 110,262 & $<0.0001$ & $* * *$ \\
\hline
\end{tabular}

Table 2 Summary of GLM results showing the association of forest increase and the landscape and geographic variables with changes in the studied landscape metrics. Each column shows the factor effect estimate (standard error) and the significant codes: 0 , '***'; 0.001 , ‘**'; 0.01, ‘*’; 0.05, '?'

\begin{tabular}{|c|c|c|c|c|c|c|c|c|}
\hline & $\begin{array}{l}\text { Forest largest } \\
\text { patch size }\end{array}$ & $\begin{array}{l}\text { Forest } \\
\text { effective mesh } \\
\text { size }\end{array}$ & $\begin{array}{l}\text { Forest } \\
\text { total } \\
\text { edge }\end{array}$ & $\begin{array}{l}\text { Number of } \\
\text { forest patches }\end{array}$ & $\begin{array}{l}\text { Shannon } \\
\text { diversity } \\
\text { index }\end{array}$ & $\begin{array}{l}\text { Percentage of forest } \\
\text { like adjacencies }\end{array}$ & $\begin{array}{l}\text { Forest mean } \\
\text { patch size }\end{array}$ & $\begin{array}{l}\text { Euclidean nearest } \\
\text { neighbour distance }\end{array}$ \\
\hline Intercept & $\begin{array}{l}272.43(14.42) \\
* * *\end{array}$ & $\begin{array}{l}162.11(14.06) \\
* * *\end{array}$ & $\begin{array}{l}92,344 \\
\quad(4706) \\
* * *\end{array}$ & $\begin{array}{l}95.35(40.2) \\
* * *\end{array}$ & $\begin{array}{l}-0.12(0.01) \\
* * *\end{array}$ & $\begin{array}{l}3.13 \\
(0.65) \\
* * *\end{array}$ & & \\
\hline $\begin{array}{l}\text { Forest increase } \\
\quad(\mathrm{FI})\end{array}$ & $\begin{array}{l}473.09(22.73) \\
* * *\end{array}$ & $\begin{array}{l}168.09(23.57) \\
* * *\end{array}$ & $\begin{array}{l}94,337 \\
(8252) \\
* * *\end{array}$ & $\begin{array}{l}57.55(7.10) \\
* * *\end{array}$ & & $\begin{array}{l}-1.67 \\
(1.11)\end{array}$ & $\begin{array}{l}-15.57 \\
(8.85)\end{array}$ & $18.39(12.13)$ \\
\hline Forest cover & $\begin{array}{l}146.06(14.67) \\
* * * *\end{array}$ & $\begin{array}{l}299.90(14.83) \\
* * * *\end{array}$ & $\begin{array}{l}-21,084 \\
(5182) \\
* * *\end{array}$ & $\begin{array}{l}-40.13(7.12) \\
* * *\end{array}$ & & & $\begin{array}{l}26.39 \\
(5.73) \\
* * *\end{array}$ & \\
\hline Crops cover & & & & $\begin{array}{l}-38.37(7.10) \\
* * *\end{array}$ & $\begin{array}{l}0.05 \\
(0.01) \\
* * *\end{array}$ & $\begin{array}{l}3.04 \\
(0.76) \\
* * *\end{array}$ & & \\
\hline $\begin{array}{l}\text { Shrub/grassland } \\
\text { cover }\end{array}$ & & & & $\begin{array}{l}-21.90(4.59) \\
* * *\end{array}$ & $\begin{array}{l}-0.02(0.01) \\
*\end{array}$ & $\begin{array}{l}1.82 \\
(0.57) \\
* *\end{array}$ & & \\
\hline Elevation & & & $\begin{array}{l}13,730 \\
\quad(7132)\end{array}$ & $\begin{array}{l}1.16 \\
(6.18)\end{array}$ & $\begin{array}{l}-0.04(0.01) \\
* *\end{array}$ & & & \\
\hline Longitude & & $\begin{array}{l}38.76(13.85) \\
* *\end{array}$ & $\begin{array}{l}-23,907 \\
(4447) \\
* * *\end{array}$ & $\begin{array}{l}-26.15(3.68) \\
* * *\end{array}$ & & $\begin{array}{l}1.26 \\
(0.59) \\
*\end{array}$ & $\begin{array}{l}13.22 \\
(5.01) \\
* *\end{array}$ & $\begin{array}{l}20.42(9.16) \\
*\end{array}$ \\
\hline Latitude & & $\begin{array}{l}-35.29(16.03) \\
*\end{array}$ & $\begin{array}{l}29,849 \\
\quad(6111) \\
* * *\end{array}$ & $\begin{array}{l}0.74 \\
(5.41)\end{array}$ & $\begin{array}{l}0.10 \\
(0.01) \\
* * *\end{array}$ & $\begin{array}{l}-3.48 \\
(0.64) \\
* * *\end{array}$ & & \\
\hline FI: forest cover & $\begin{array}{l}221.9(16.22) \\
* * *\end{array}$ & $\begin{array}{l}469.65(19.67) \\
* * * *\end{array}$ & $\begin{array}{l}-88,460 \\
\quad(6561) \\
* * *\end{array}$ & $\begin{array}{l}-53.97(5.59) \\
* * *\end{array}$ & & & $\begin{array}{l}26.99 \\
(6.32) \\
* * *\end{array}$ & \\
\hline FI: crops cover & & & & & & $\begin{array}{l}-4.10 \\
(1.12) \\
* * *\end{array}$ & & \\
\hline FI: elevation & & & $\begin{array}{l}43,153 \\
(12026) \\
* * *\end{array}$ & $\begin{array}{l}29.26(10.19) \\
* *\end{array}$ & & & & \\
\hline FI: longitude & & $\begin{array}{l}44.45(19.25) \\
*\end{array}$ & $\begin{array}{l}-18,909 \\
(6167) \\
* *\end{array}$ & & & & & $\begin{array}{l}-25.01(11.52) \\
*\end{array}$ \\
\hline FI: latitude & & $\begin{array}{l}-154.47(23.45) \\
* * *\end{array}$ & $\begin{array}{l}67,268 \\
(8434) \\
* * *\end{array}$ & $\begin{array}{l}14.61(6.72) \\
*\end{array}$ & & & & \\
\hline Model fit $\boldsymbol{\nabla}$ & & & & & & & & \\
\hline $\begin{array}{l}\text { Residual } \\
\quad \text { standard } \\
\text { error }\end{array}$ & 341.4 & 324.5 & 10,350 & 0.75 & 0.31 & 14.35 & 132.8 & 207.7 \\
\hline$R$-squared & 0.85 & 0.84 & 0.31 & 0.27 & 0.17 & 0.16 & 0.08 & 0.02 \\
\hline AIC model & $10,913.19$ & $10,826.24$ & $19,512.46$ & 8882.77 & 395.77 & 6141.62 & 9494.42 & 7936.39 \\
\hline AIC null model & $12,280.84$ & $12,212.15$ & $19,771.98$ & 9101.12 & 524.99 & 6256.30 & 9552.35 & 7943.53 \\
\hline
\end{tabular}


a

\section{Patch coalescence}

b

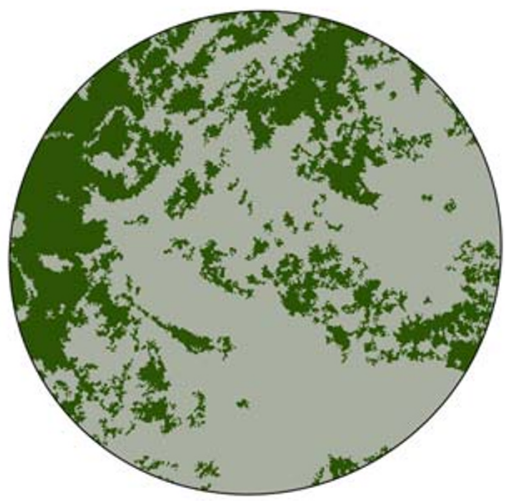

\section{Patch proliferation}

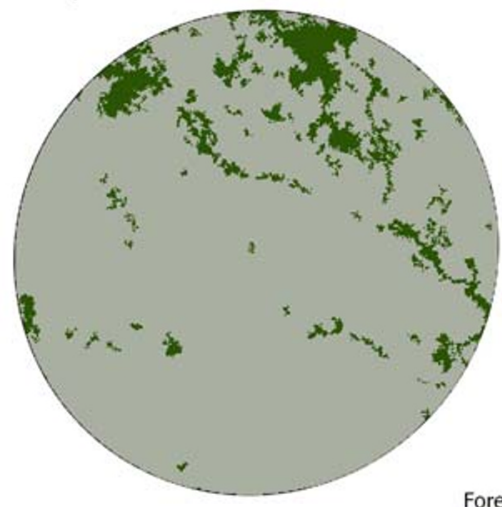

Forest growth process $\square$ No forest

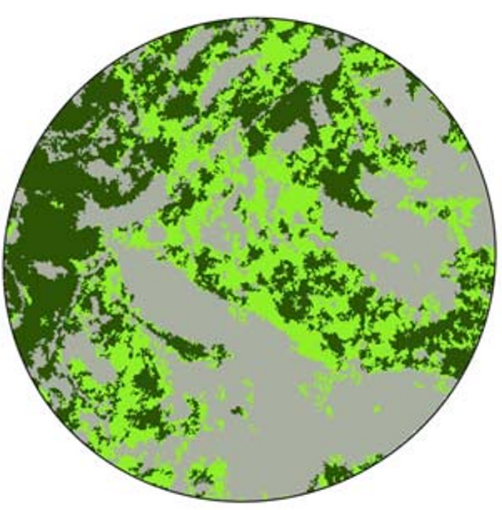

Forest increase 1990-2012

2012
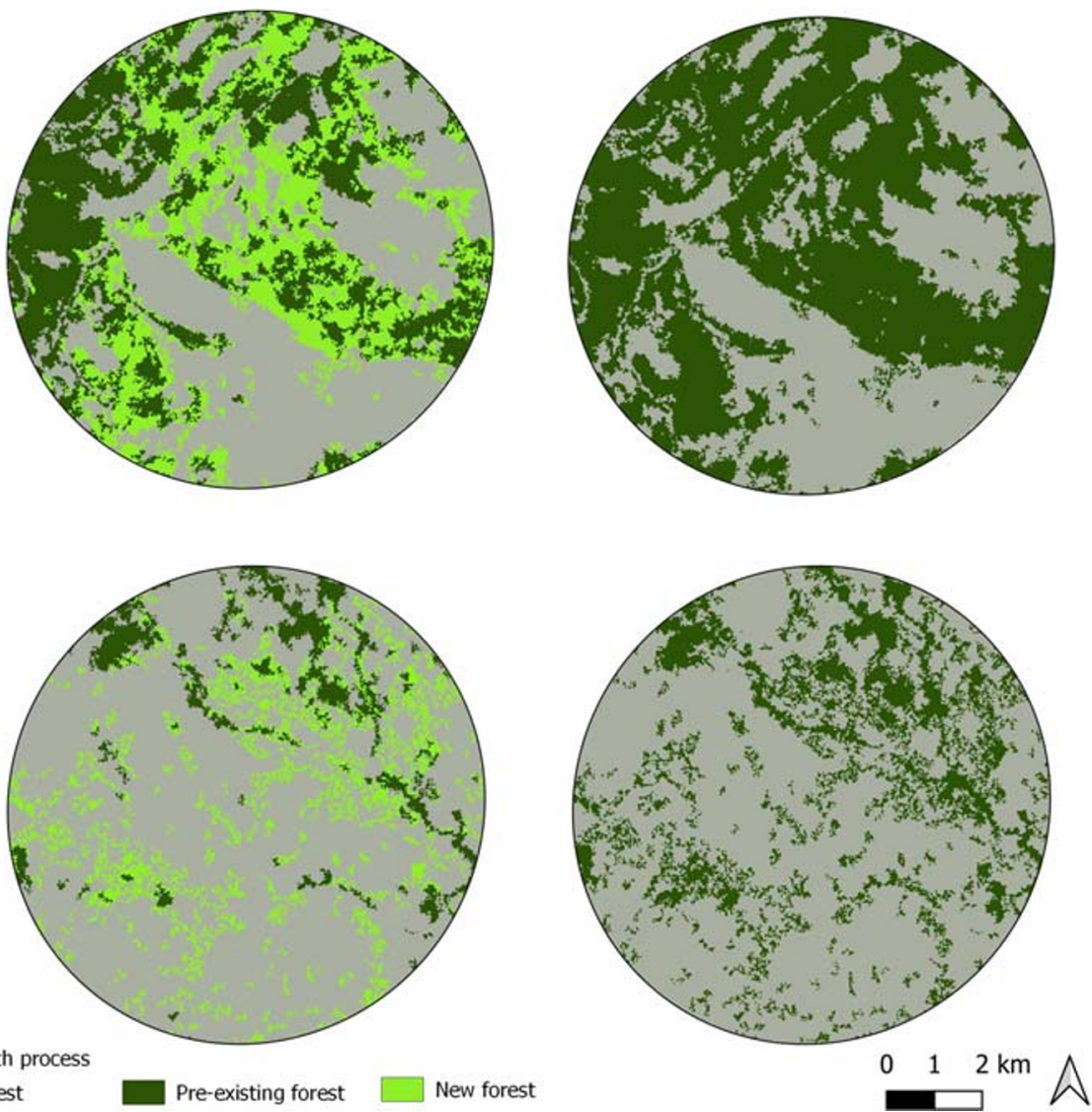

Fig. 1 Examples of forest-dominated and non-dominated landscapes, where pre-existing patch coalescence and new patch proliferation were respectively observed

adjacencies. Further, the increase in effective mesh size following forest cover increase was higher the higher the longitude and latitude (Fig. 4 a and b, Appendix 2, respectively). Contrarily, the increase in the forest total edge in relation to forest cover increase was higher the lower the longitude and latitude (Fig. 4 c and d, Appendix 2, respectively). The increase in the number of forest patches following that in forest cover was higher the lower the latitude (Fig. 4e, Appendix 2).

Finally, elevation showed a positive association with the increase in the forest total edge, but negative with that in the Shannon diversity index. The increase in both forest total edge and in the number of forest patches following that in forest cover was highest between 500 and $1000 \mathrm{~m}$ above sea level (Fig. 5a, b; Appendix 2).

\section{Discussion}

Our results confirm our first hypothesis that European landscapes experiencing forest recovery in the last decades also exhibit a significant decrease in their land cover diversity, and an increase in both forest defragmentation and connectivity. However, not all these changes are directly attributable to forest increase, as our models show that some of them were only concurrent with it. This is the case of land cover diversity, which decreases in landscapes where the forest increased, yet this decrease is not associated with forest increase or even to forest cover as suggested in previous regional-scale studies (e.g. Marull et al. 2015; Otero et al. 2015). Instead, we observe a significant effect of other land cover categories, namely cropland and scrub-grassland, on the land cover diversity of these landscapes. This striking result brings some additional dimensions to the complex debate about the conservation of agroforestry mosaics, considered as biodiversity hotspots in Europe and especially threatened by afforestation (Marull et al. 2015; Otero et al. 2015). Positive association with cropland cover suggests that forest recovery leads to higher landscape diversity in cropland-dominated landscapes that often result from agricultural intensification (Perfecto and Vandermeer 2010; Otero et al. 2015). In contrast, its negative association with scrub and grassland cover, frequently originated from crop and pasture abandonment, might indicate that forest increase is especially detrimental for landscape diversity where traditional 


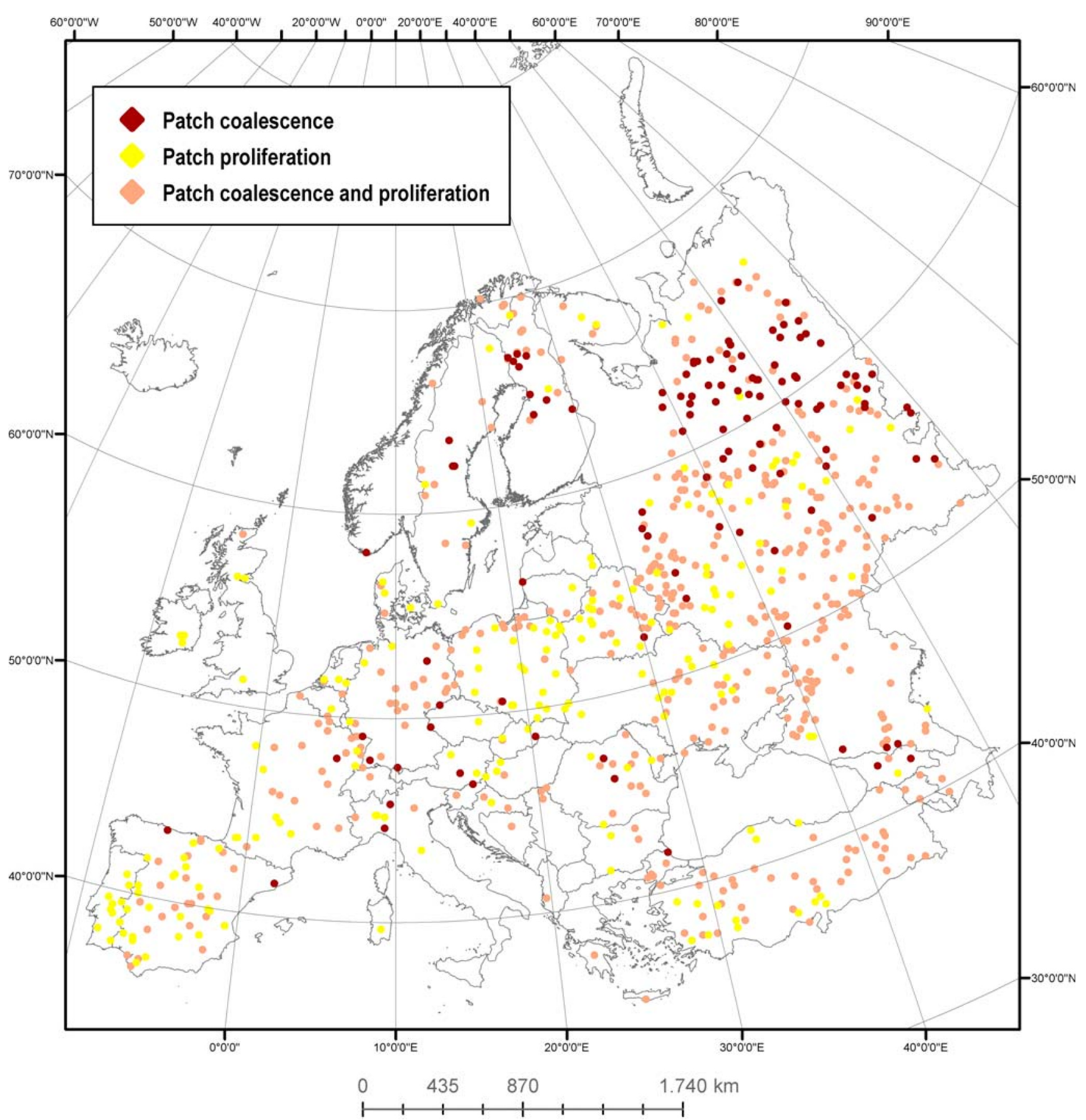

Fig. 2 Distribution of the study landscapes classified as patch coalescence (effective mesh size increase over the median of the sample while number of forest patches under the median of the sample), patch proliferation (effective mesh size increase under the median of the sample while number of forest patches over the median of the sample) and both patch coalescence and proliferation (the remaining landscapes)

latitudinal gradient in land cover diversity $(r$-Spearman $=-$ $0.21, p<0.001)$ : i.e. forest gain might increase land cover diversity more in the less diverse northern landscapes than in the southern ones.

Results regarding the effects of forest increase on changes in forest attributes suggest the coexistence of contrasting landscape processes on forest spatial pattern. On the one hand, forest gain determines a significant increase in both forest
Positive association with latitude might be due to the inverse 
largest patch and effective mesh size, which are mostly related to the growth and coalescence of pre-existing forest patches indicative of forest defragmentation. On the other hand, forest recovery also determines an increase in the number of forest patches and in total forest edge. These results might be viewed, paradoxically, indicative of forest fragmentation due to small patch proliferation, as edge per area unit increases more rapidly with new small isolated patches than with the growth of old big patches. Fahrig (2003) described a similar paradoxical situation regarding the opposite case of habitat loss, which might determine both habitat fragmentation and defragmentation depending on the spatial loss pattern (i.e. the loss and fragmentation of big versus small or nearby versus far habitat patches). The coexistence of these landscape patterns is probably the reason that there are non-significant changes in mean patch size associated with forest increase across Europe.

Our study also demonstrates that these landscape changes associated with forest increase depend on the original landscape composition (especially forest, but also cropland cover) and on a set of geographic and topographic variables. The first point illustrates the above-mentioned dichotomy of pre-existing patch growth and coalescence versus new patch proliferation associated with forest increase (Fig. 1). Thus, this last mostly determines patch growth and coalescence in forest-dominated $(>50 \%$ of forest cover) landscapes, but new patch proliferation in nonforest-dominated ones. Regarding the second point, our study shows the existence of significant geographic gradients in landscape change due to afforestation. While defragmentation (i.e. forest patch growth and coalescence) is especially concentrated northwards, new patch proliferation (indicated by increasing the patch number and, secondarily, by total edge) particularly affects the lowest latitudes (see Fig. 2). This pattern is probably due to a combination of climate and human land-use legacy, since new forests mostly are originated from old pastures and wet grasslands in northern landscapes with colder climates while they come mostly from croplands in the rest of the landscapes (M. Palmero-Iniesta, unpublished results). Moreover, pre-existing patch growth and coalescence concentrate eastwards where the landscape matrix is a forest-cropland mosaic, while the new patch proliferation is especially important in the western boundary where landscapes are especially affected by intense urbanization and fragmentation by infrastructures (Jongman 2002; Jaeger et al. 2016). Still, the study indicates that forest increase especially determines the new patch proliferation (as indicated by the increase in the total edge and in the number of patches; Fig. 5, Appendix 2) in medium elevations, probably because of a concentration of crop abandonment in uplands as suggested in previous works (Basnou et al. 2013; Cervera et al. 2019).

These results are, in turn, relevant for improving the strategies of forest biodiversity conservation, as they put in value the importance of considering the original composition of landscape and the socio-environmental context. Yet, the spatial arrangement of these new forests may influence forest resilience by increasing the functional diversity of tree species and by modifying the connectivity, centrality and modularity of forest landscapes (Messier et al. 2019). Forest defragmentation in already highly forested landscapes will clearly promote the recovery of forest specialist species commonly occupying large and connected forest areas and often of large conservation concern (e.g. Saura and Pascual-Hortal 2007; Gil-Tena et al. 2013; Deinet et al. 2017), and this will help to reconnect both the existing populations and potential habitats, particularly in Northern and Eastern Europe and in main mountain ranges, thus reinforcing the ecological network of protected areas in Europe (EEA 2012). In contrast, the proliferation of new forest patches in lowland, highly anthropized landscapes in Southern and Western Europe might favour forest generalist species that commonly have less conservation concern, and even non-forest and alien species (Guirado et al. 2006; Basnou et al. 2015; Regos et al. 2016; Liebhold et al. 2017). Conversely, the new patch proliferation observed southwards and westwards suggests an increase in functional connectivity among forests (e.g. seed dispersal potential) and may facilitate migration and gene flow among tree populations in response to climate change (Breed et al. 2011) while, at the same time, preventing, especially in the south, the danger of the coalescence of large forest areas in light of the propagation of extreme wildfires (Bowen et al. 2007). Moreover, the new habitat availability may be especially relevant in Southern Europe, as habitat loss and fragmentation effects on species density and/or diversity is greatest in areas with high maximum temperatures and in areas where average rainfall has decreased more over time (see Mantyka-Pringle et al. 2012).

\section{Conclusion}

To sum up, our study shows that forest recovery in Europe is guessed by landscape changes in recently afforested landscapes. However, these changes are more complex than expected and they cannot be solely attributable to forest increase, but also to the original landscape composition and position across elevational and geographical gradients across the mainland.

Results may be especially relevant for the preservation of forest biodiversity and ecosystem services since they highlight the importance of the landscape context on the new forest spatial distribution pattern including forest fragmentation and connectivity and landscape diversity. Specific management policies might help to redirect these trends by designing both large forest recovery and priority connection areas in order to ensure large patch coalescence yet combined with prevention plans to avoid the deleterious effects of forest continuity in some of these regions (e.g. wildfires in Southern Europe; Duane et al. 2016).

Acknowledgements We are grateful to the Global Land Cover Facility (GLCF) from the University of Maryland for freely and openly facilitating the Landsat-based Forest Cover Change datasets, especially to 
Hansen et al. (2013) and Kim et al. (2014). We are equally grateful to the Climate Change Initiative of the European Spatial Agency (ESA CCILC) for the elaboration and facilitation of the Land Cover time series.

Funding information This research was supported by the projects FORASSEMBLY (CGL2015-70558-P), SPONFOREST (APCIN 2016_0174) and NEWFORLAND (RTI2018-099397-B-C2 2 MCIU/AEI/ERDF, EU). M. Palmero-Iniesta was funded by a predoctoral grant, FI-AGAUR 2018 (BDNS 417789), from the Generalitat de Catalunya.
Data availability The datasets generated during and/or analysed during the current study are available in the Mendeley repository, https://doi.org/ $10.17632 /$ hwntrn78vc. 1

\section{Compliance with ethical standards}

Conflict of interest The authors declare that they have no conflict of interest.

\section{Appendix 1}

Table 3 Summary of the composition of the 752 study landscapes randomly selected across Europe

\begin{tabular}{cllll}
\hline Forest (\%) & \multicolumn{1}{c}{ Agriculture (\%) } & Agroforestry mosaics (\%) & Grassland (\%) & Settlement (\%) \\
Min., 0.00 & Min., 0.00 & Min., 0.00 & Min., 0.00 & Min., 0.00 \\
1st Qu., 2.99 & 1st Qu., 1.64 & 1st Qu., 0.72 & 1st Qu., 0.00 & 1st Qu., 0.00 \\
Median, 26.49 & Median, 25.99 & Median, 5.49 & Median, 0.41 & Median, 0.00 \\
Mean, 37.03 & Mean, 37.35 & Mean, 9.32 & Mean, 6.18 & Mean, 0.85 \\
3rd Qu., 68.75 & 3rd Qu., 70.97 & 3rd Qu., 14.99 & 3rd Qu., 5.28 & 3rd Qu., 0.21 \\
Max., 100.00 & Max., 100.00 & Max., 86.30 & Max., 93.63 & Max., 60.78 \\
Wetland (\%) & Sparse vegetation (\%) & Shrubland (\%) & Bare area (\%) & Water (\%) \\
Min., 0.00 & Min., 0.00 & Min., 0.00 & Min., 0.00 & Min., 0.00 \\
1st Qu., 0.00 & 1st Qu., 0.00 & 1st Qu., 0.00 & 1st Qu., 0.00 & 1st Qu., 0.00 \\
Median, 0.00 & Median, 0.00 & Median, 0.00 & Median, 0.00 & Median, 0.00 \\
Mean, 2.76 & Mean, 1.17 & Mean, 0.52 & Mean, 0.31 & Mean, 2.46 \\
3rd Qu., 0.21 & 3rd Qu., 0.00 & 3rd Qu., 0.00 & 3rd Qu., 0.00 & 3rd Qu., 0.62 \\
Max., 76.65 & Max., 54.27 & Max., 71.88 & Max., 30.38 & Max., 98.76 \\
\hline
\end{tabular}

Table 4 Correlation matrix with a Spearman rank $(r)$ for the landscape covariates used in the general lineal models

Forest increase (ha) $\quad$ Forest cover (\%) $\quad$ Crop cover (\%) $\quad$ Shrub/grassland cover (\%) $\quad$ Elevation (m) $\quad$ Long. $\left({ }^{\circ}\right) \quad$ Lat. $\left(\left(^{\circ}\right)\right.$

\begin{tabular}{|c|c|c|c|c|c|c|c|}
\hline Forest increase (ha) & 1.00 & & & & & & \\
\hline Forest cover $(\%)$ & 0.45 & 1.00 & & & & & \\
\hline Cropland cover $(\%)$ & -0.35 & -0.64 & 1.00 & & & & \\
\hline Shrub/grass. cover $(\%)$ & -0.11 & -0.15 & -0.31 & 1.00 & & & \\
\hline Elevation (m) & -0.15 & 0.04 & -0.14 & 0.13 & 1.00 & & \\
\hline Longitude $\left(^{\circ}\right)$ & 0.23 & 0.17 & -0.09 & -0.08 & -0.14 & 1.00 & \\
\hline Latitude $\left({ }^{\circ}\right)$ & 0.37 & 0.46 & -0.38 & 0.03 & -0.52 & 0.43 & 1.00 \\
\hline
\end{tabular}


Table 5 Components of the plausible models (delta $<2$ ) after model selection for the general lineal models performed for each landscape metric. Factor code: crop cover (1), forest cover (2), forest increase = FI
(3), latitude (4), longitude (5), elevation (6), grassland/shrubland cover (7), crop cover: FI (8), forest cover: FI (9), latitude: FI (10), longitude: FI (11), elevation: FI (12), grassland/shrubland cover: FI (13)

\begin{tabular}{|c|c|c|c|c|c|}
\hline Component models: & df & $\log \mathrm{Lik}$ & $\mathrm{AICc}$ & Delta & Weight \\
\hline \multicolumn{6}{|l|}{ Largest patch size } \\
\hline $2 / 3 / 9$ & 5 & -5451.56 & $10,913.19$ & 0.00 & 0.07 \\
\hline $2 / 3 / 5 / 9$ & 6 & -5451.10 & $10,914.32$ & 1.13 & 0.04 \\
\hline $1 / 2 / 3 / 8 / 9$ & 7 & -5450.27 & $10,914.69$ & 1.50 & 0.03 \\
\hline $2 / 3 / 4 / 9$ & 6 & -5451.39 & $10,914.90$ & 1.71 & 0.03 \\
\hline $2 / 3 / 6 / 9$ & 6 & -5451.51 & $10,915.13$ & 1.93 & 0.03 \\
\hline \multicolumn{6}{|l|}{ Effective mesh size } \\
\hline $2 / 3 / 4 / 5 / 9 / 10 / 11$ & 9 & -5404.00 & $10,826.24$ & 0.00 & 0.17 \\
\hline $1 / 2 / 3 / 4 / 5 / 9 / 10 / 11$ & 10 & -5403.53 & $10,827.36$ & 1.12 & 0.10 \\
\hline $1 / 2 / 3 / 4 / 5 / 8 / 9 / 10 / 11$ & 11 & -5402.68 & $10,827.72$ & 1.48 & 0.08 \\
\hline $2 / 3 / 4 / 5 / 7 / 9 / 10 / 11$ & 10 & -5403.81 & $10,827.92$ & 1.68 & 0.07 \\
\hline \multicolumn{6}{|l|}{ Mean patch area } \\
\hline $2 / 3 / 5 / 9$ & 6 & -4741.15 & 9494.42 & 0.00 & 0.07 \\
\hline $2 / 3 / 5 / 9 / 11$ & 7 & -4740.55 & 9495.25 & 0.83 & 0.05 \\
\hline $1 / 2 / 3 / 5 / 9$ & 7 & -4740.87 & 9495.90 & 1.48 & 0.03 \\
\hline $1 / 2 / 3 / 5 / 8 / 9$ & 8 & -4739.91 & 9496.00 & 1.58 & 0.03 \\
\hline $2 / 3 / 5 / 7 / 9$ & 7 & -4741.01 & 9496.16 & 1.74 & 0.03 \\
\hline $2 / 3 / 4 / 5 / 9$ & 7 & -4741.04 & 9496.23 & 1.81 & 0.03 \\
\hline $2 / 3 / 5 / 7 / 9 / 13$ & 8 & -4740.07 & 9496.34 & 1.92 & 0.03 \\
\hline \multicolumn{6}{|l|}{ Total edge } \\
\hline $2 / 3 / 4 / 5 / 6 / 9 / 10 / 11 / 12$ & 11 & -9742.98 & $19,512.46$ & 0.00 & 0.27 \\
\hline $2 / 3 / 4 / 5 / 6 / 7 / 9 / 10 / 11 / 12$ & 12 & -9745.46 & $19,513.27$ & 0.81 & 0.18 \\
\hline $1 / 2 / 3 / 4 / 5 / 6 / 9 / 10 / 11 / 12$ & 12 & -9744.88 & $19,514.19$ & 1.73 & 0.11 \\
\hline $1 / 2 / 3 / 4 / 5 / 6 / 7 / 8 / 9 / 10 / 11 / 12$ & 14 & -9742.88 & $19,514.34$ & 1.88 & 0.11 \\
\hline \multicolumn{6}{|l|}{ Number of patches } \\
\hline $1 / 2 / 3 / 4 / 5 / 6 / 7 / 9 / 10 / 12$ & 12 & -4429.17 & 8882.77 & 0.00 & 0.14 \\
\hline $1 / 2 / 3 / 5 / 6 / 7 / 9 / 12$ & 10 & -4431.64 & 8883.58 & 0.80 & 0.10 \\
\hline $1 / 2 / 3 / 5 / 6 / 7 / 8 / 9 / 12$ & 11 & -4431.12 & 8884.60 & 1.83 & 0.06 \\
\hline $1 / 2 / 3 / 4 / 5 / 6 / 7 / 8 / 9 / 10 / 12$ & 13 & -4429.10 & 8884.68 & 1.91 & 0.06 \\
\hline \multicolumn{6}{|c|}{ Euclidean nearest neighbour distance } \\
\hline $3 / 5 / 11$ & 5 & -3963.14 & 7936.39 & 0.00 & 0.04 \\
\hline $1 / 3 / 5 / 11$ & 6 & -3962.37 & 7936.88 & 0.50 & 0.03 \\
\hline 5 & 3 & -3965.51 & 7937.06 & 0.67 & 0.03 \\
\hline $1 / 3 / 4 / 5 / 11$ & 7 & -3961.59 & 7937.38 & 0.99 & 0.02 \\
\hline $1 / 5$ & 4 & -3964.71 & 7937.50 & 1.11 & 0.02 \\
\hline $3 / 4 / 5 / 11$ & 6 & -3962.80 & 7937.75 & 1.36 & 0.02 \\
\hline $2 / 3 / 5 / 11$ & 6 & -3962.89 & 7937.92 & 1.54 & 0.02 \\
\hline $1 / 4 / 5$ & 5 & -3964.01 & 7938.13 & 1.74 & 0.02 \\
\hline $3 / 5 / 6 / 11$ & 6 & -3963.06 & 7938.26 & 1.87 & 0.01 \\
\hline \multicolumn{6}{|l|}{ Percentage of like-adjacencies } \\
\hline $1 / 3 / 4 / 5 / 7 / 8$ & 8 & -3062.71 & 6141.62 & 0.00 & 0.05 \\
\hline $1 / 3 / 4 / 5 / 6 / 7 / 8 / 12$ & 10 & -3060.87 & 6142.04 & 0.42 & 0.04 \\
\hline $1 / 3 / 4 / 5 / 7 / 8 / 10$ & 9 & -3062.22 & 6142.69 & 1.07 & 0.03 \\
\hline $1 / 2 / 3 / 4 / 5 / 7 / 8$ & 9 & -3062.27 & 6142.78 & 1.16 & 0.03 \\
\hline $1 / 3 / 4 / 5 / 7 / 8 / 13$ & 9 & -3062.34 & 6142.91 & 1.30 & 0.03 \\
\hline $1 / 3 / 4 / 5 / 6 / 7 / 8 / 12 / 13$ & 11 & -3060.48 & 6143.32 & 1.70 & 0.02 \\
\hline $1 / 2 / 3 / 4 / 5 / 6 / 7 / 8 / 12$ & 11 & -3060.53 & 6143.42 & 1.80 & 0.02 \\
\hline $1 / 3 / 4 / 5 / 7 / 8 / 11$ & 9 & -3062.60 & 6143.45 & 1.83 & 0.02 \\
\hline $1 / 3 / 4 / 5 / 6 / 7 / 8$ & 9 & -3062.65 & 6143.55 & 1.93 & 0.02 \\
\hline $1 / 3 / 4 / 6 / 7 / 8 / 12$ & 9 & -3062.66 & 6143.56 & 1.94 & 0.02 \\
\hline \multicolumn{6}{|l|}{ Shannon diversity index } \\
\hline $1 / 4 / 6 / 7$ & 6 & -191.83 & 395.77 & 0.00 & 0.07 \\
\hline $1 / 3 / 4 / 6 / 7$ & 7 & -191.51 & 397.17 & 1.40 & 0.03 \\
\hline $1 / 2 / 4 / 6 / 7$ & 7 & -191.75 & 397.65 & 1.89 & 0.03 \\
\hline $1 / 3 / 4 / 6 / 7 / 8$ & 8 & -190.75 & 397.70 & 1.93 & 0.03 \\
\hline $1 / 4 / 5 / 6 / 7$ & 7 & -191.80 & 397.74 & 1.98 & 0.02 \\
\hline
\end{tabular}




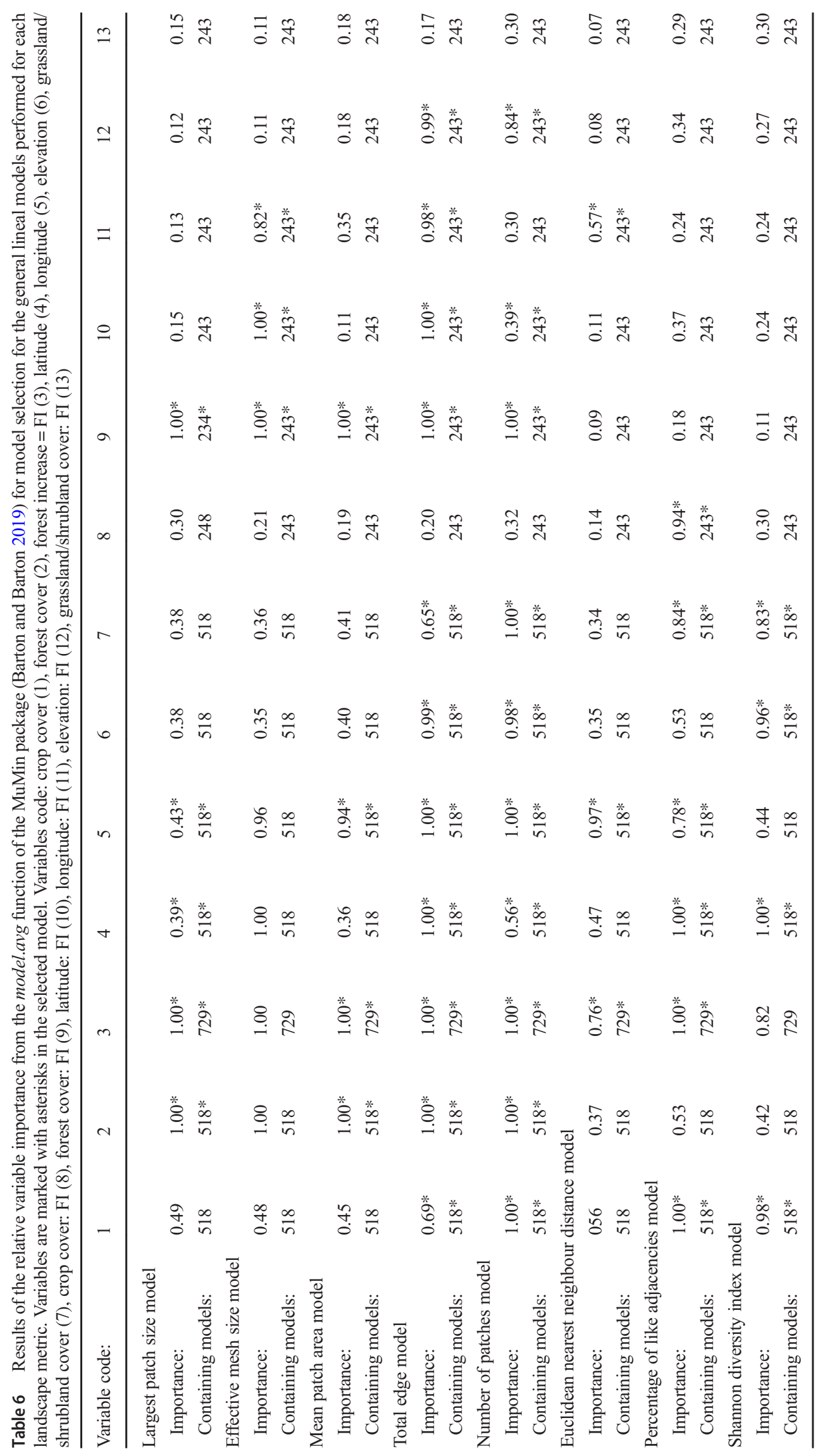




\section{Appendix 2}

a
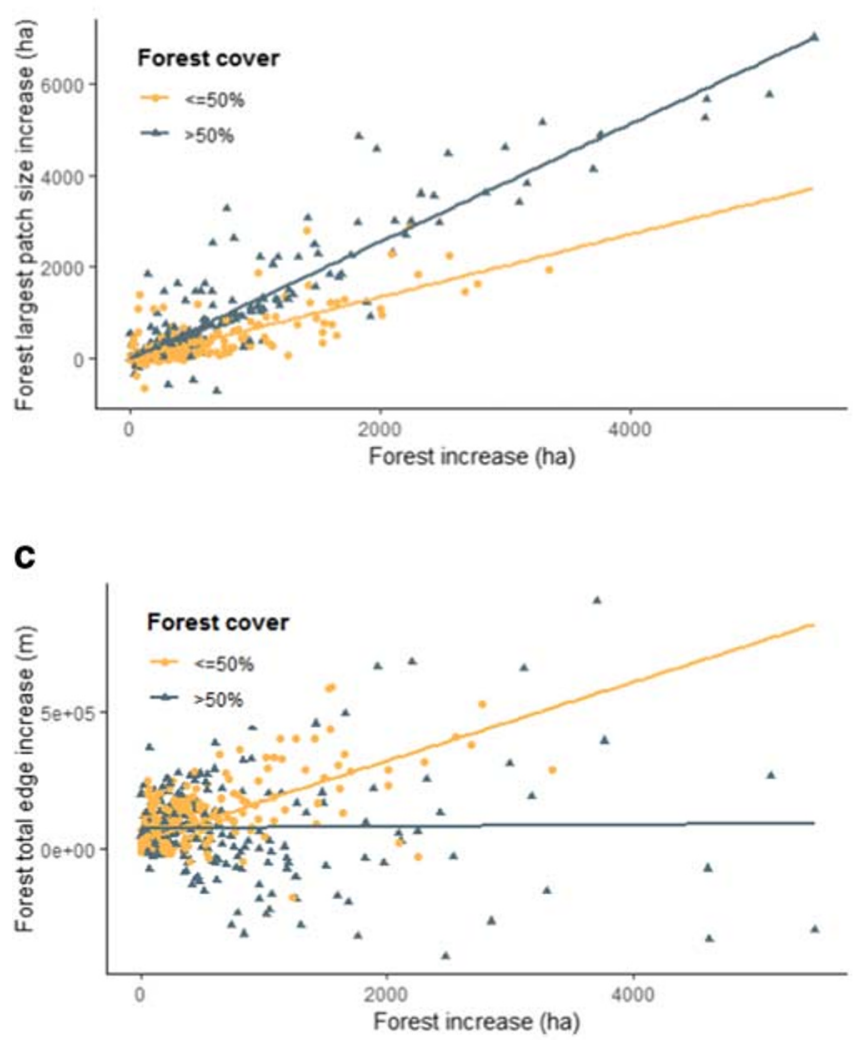

b

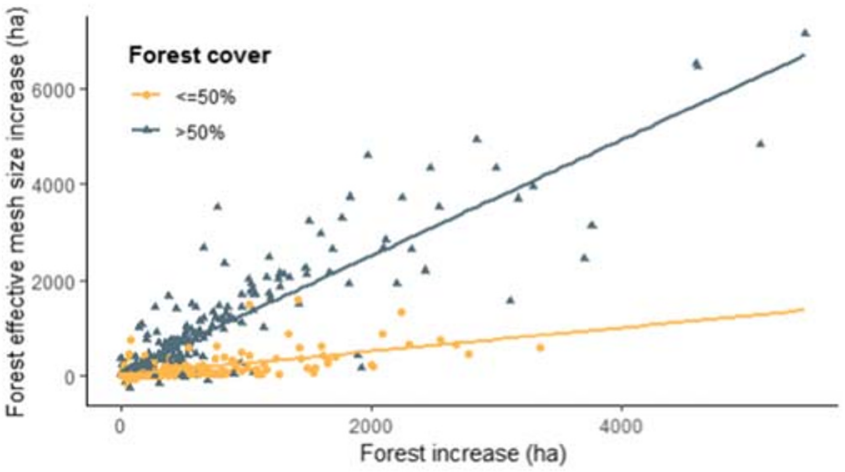

d

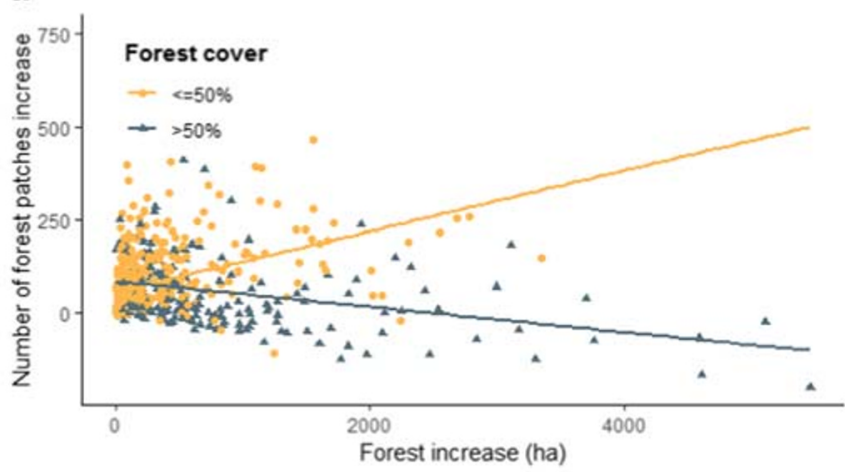

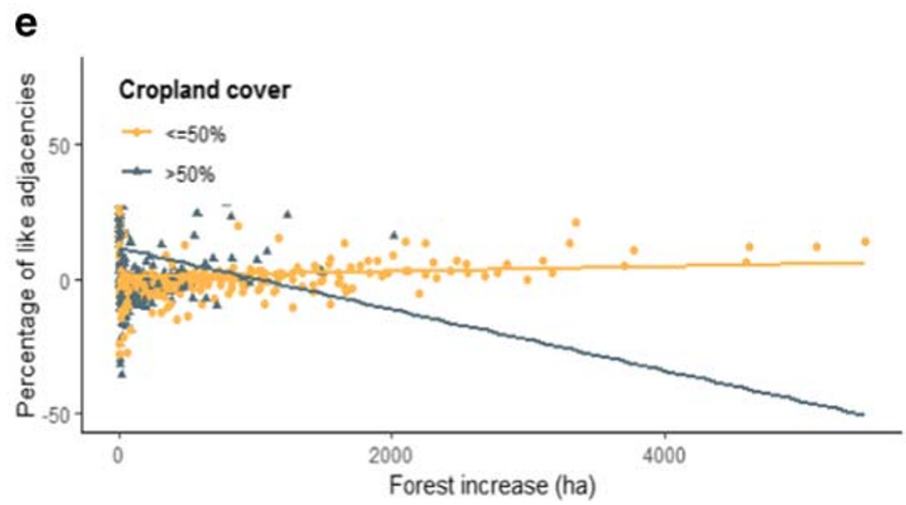

Fig. 3 Association of forest increase between 1990 and 2012 with the increase in forest largest patch size (a), forest effective mesh size (b), forest total edge (c) and the number of forest patches (d) in the study landscapes, for two ranges of forest cover percentage (a, b, c, d) and cropland cover (e) 
$\mathbf{a}$

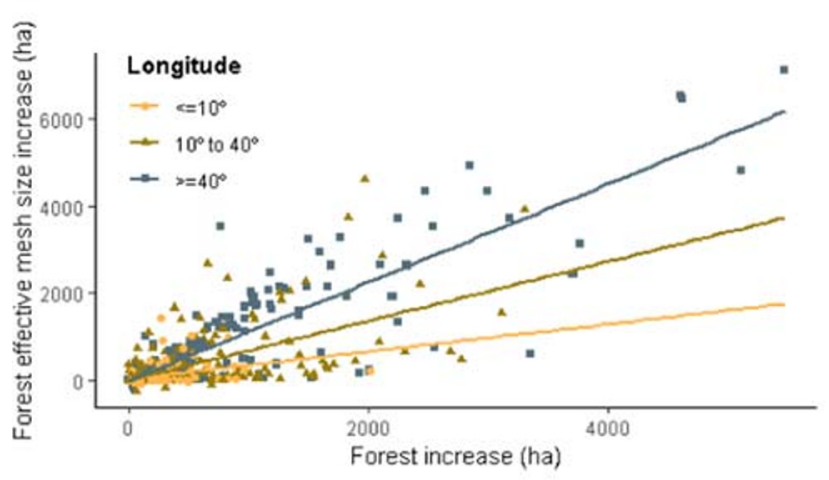

C

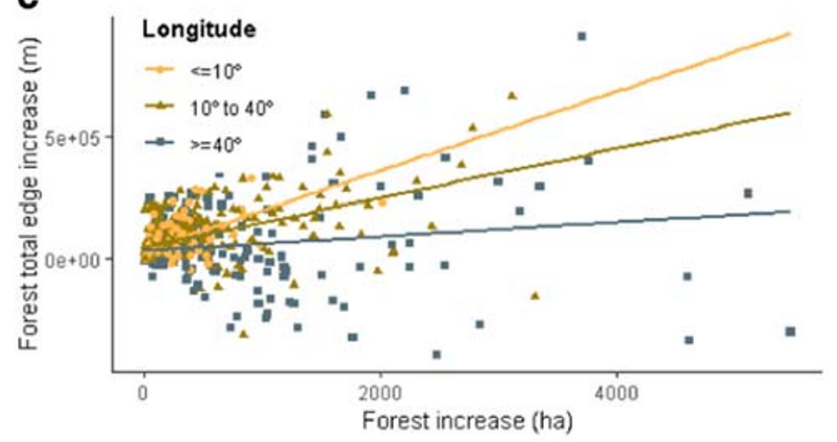

b

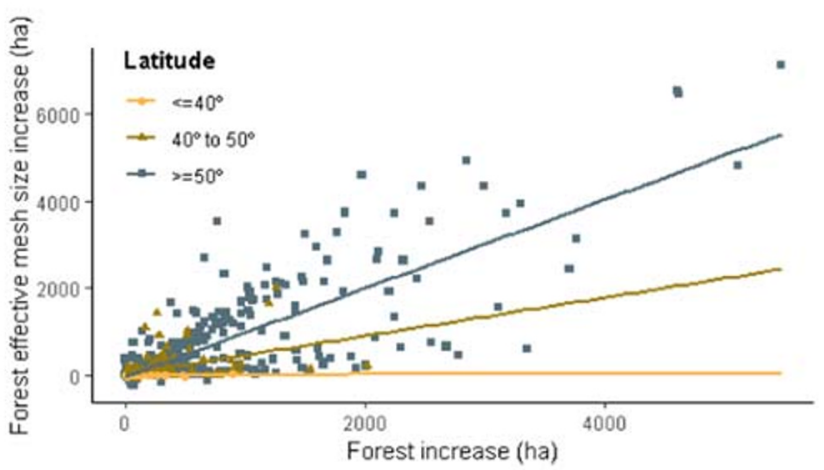

d

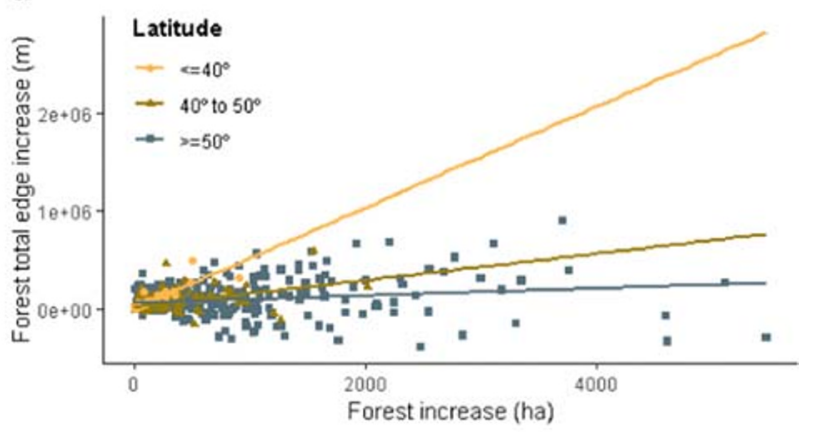

e

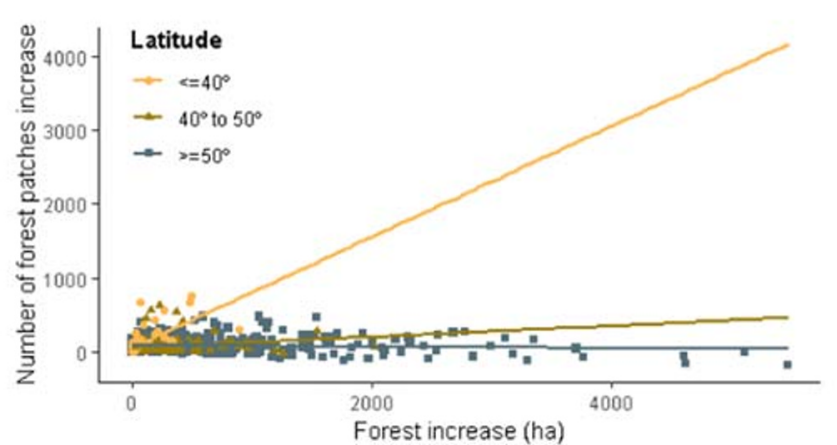

Fig. 4 Association of forest increase between 1990 and 2012 in the study landscapes with their increase in forest effective mesh size (a, b), in forest total edge (c, $\mathbf{d})$ and number of forest patches (e) for diverse latitude and longitude ranges

a

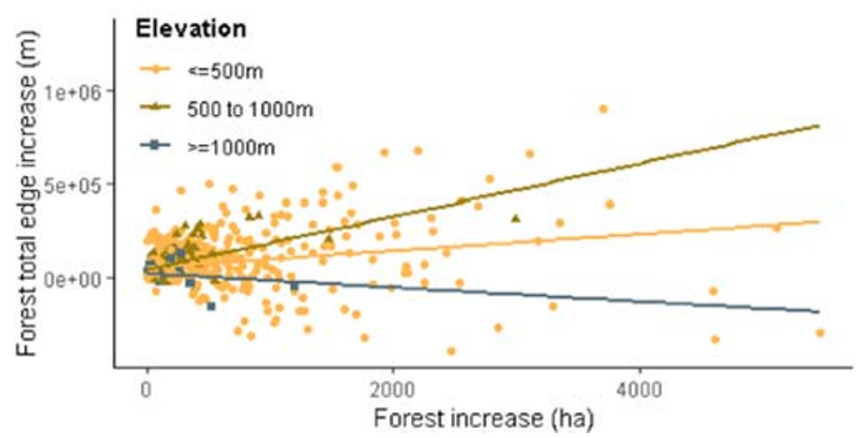

b

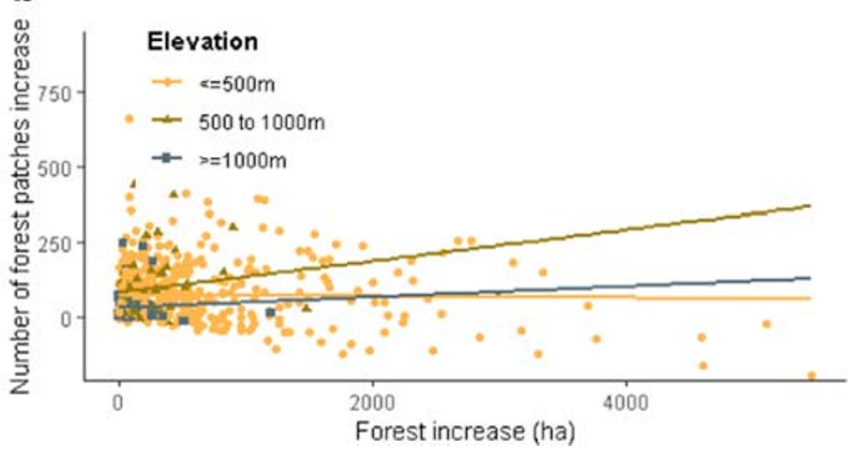

Fig. 5 Association of forest increase between 1990 and 2012 in the study landscapes with their increase in forest total edge (a) and in the number of forest patches increase (b) for diverse elevation ranges 


\section{References}

Barton K, Barton MK (2019) Package “MuMIn.” Multi-model inference version 1

Baśnou C, Álvarez E, Bagaria G et al (2013) Spatial patterns of land use changes across a Mediterranean metropolitan landscape: implications for biodiversity management. Environ Manag 52:971-980. https://doi.org/10.1007/s00267-013-0150-5

Basnou C, Iguzquiza J, Pino J (2015) Examining the role of landscape structure and dynamics in alien plant invasion from urban Mediterranean coastal habitats. Landsc Urban Plan 136:156-164. https://doi.org/10.1016/j.landurbplan.2014.12.001

Boulinier T, Nichols JD, Hines JE et al (2001) Forest fragmentation and bird community dynamics: inference at regional scales. Ecology 82: 1159-1169. https://doi.org/10.1890/0012-9658(2001)082[1159: FFABCD]2.0.CO;2

Bowen ME, McAlpine CA, House APN, Smith GC (2007) Regrowth forests on abandoned agricultural land: a review of their habitat values for recovering forest fauna. Biol Conserv 140:273-296. https://doi.org/10.1016/j.biocon.2007.08.012

Breed MF, Ottewell KM, Gardner MG, Lowe AJ (2011) Clarifying climate change adaptation responses for scattered trees in modified landscapes. J Appl Ecol 48:637-641. https://doi.org/10.1111/j. 1365-2664.2011.01969.x

Cervera T, Pino J, Marull J, Padró R, Tello E (2019) Understanding the long-term dynamics of forest transition: from deforestation to afforestation in a Mediterranean landscape (Catalonia, 1868-2005). Land Use Policy 80:318-331

Crawley MJ (2007) The R book. In: The R book. John Wiley \& Sons, Ltd, pp 1-942

Debinski DM, Holt RD (2005) Review: A survey and overview of habitat fragmentation experiments. Conserv Biol 14:342-355

Deinet S, Ieronymidou C, McRae L et al (2017) Wildlife comeback in Europe: the recovery of selected mammal and bird species. Final rep to Rewilding Eur by ZSL. BirdLife Int Eur Bird Census Counc London, UK ZSL

Diogo V, Koomen E (2016) Land cover and land use indicators: review of available data. OECD Green Growth Pap No 2016/03, OECD Publ Paris. https://doi.org/10.1787/5jlr2z86r5xw-en

Duane A, Aquilué N, Gil-Tena A, Brotons L (2016) Integrating fire spread patterns in fire modelling at landscape scale. Environ Model Softw 86:219-231. https://doi.org/10.1016/j.envsoft.2016. 10.001

EEA (2016a) Environmental indicator. EEA Report 30/2016. European Environment Agency, Copenhagen, Denmark, 60 pp.

EEA (2016b) European forest ecosystems: state and trends. EEA Report 30/2016. European Environment Agency, Copenhagen, Denmark, $128 \mathrm{pp}$.

EEA (2012) Protected areas in Europe - an overview. EEA Report No 5/2012. European Environment Agency, Copenhagen, Denmark, $130 \mathrm{pp}$.

Eggleston HS, Buendia L, Miwa K, et al (2006) 2006 IPCC - guidelines for national greenhouse gas inventories. Japan

ESA (2017) CCI land cover product user guide version 2.0. available at: http://maps.elie.ucl.ac.be/CCI/viewer/download/ESACCI-LC-Ph2PUGv2_2.0.pdf, last access: 10 November 2019

Fahrig L (2003) Effects of habitat fragmentation on biodiversity. Annu Rev Ecol Evol Syst 34:487-515. https://doi.org/10.1146/annurev. ecolsys.34.011802.132419

Fahrig L (2017) Ecological responses to habitat fragmentation per se. Annu Rev Ecol Evol Syst 48:1-23. https://doi.org/10.1146/ annurev-ecolsys-110316-022612

Falcucci A, Maiorano L, Boitani L (2007) Changes in land-use/landcover patterns in Italy and their implications for biodiversity conservation. Landsc Ecol 22:617-631. https://doi.org/10.1007/ s10980-006-9056-4

Fernandes MR, Aguiar FC, Ferreira MT (2011) Assessing riparian vegetation structure and the influence of land use using landscape metrics and geostatistical tools. Landsc Urban Plan 99:166-177. https://doi. org/10.1016/j.landurbplan.2010.11.001

Gerard F, Petit S, Smith G et al (2010) Land cover change in Europe between 1950 and 2000 determined employing aerial photography. Prog Phys Geogr 34:183-205. https://doi.org/10.1177/ 0309133309360141

Geri F, Rocchini D, Chiarucci A (2010) Landscape metrics and topographical determinants of large-scale forest dynamics in a Mediterranean landscape. Landsc Urban Plan 95:46-53. https:// doi.org/10.1016/j.landurbplan.2009.12.001

Gil-Tena A, Brotons L, Fortin MJ, Burel F, Saura S (2013) Assessing the role of landscape connectivity in recent woodpecker range expansion in Mediterranean Europe: Forest management implications. Eur J For Res 132:181-194. https://doi.org/10.1007/s10342-012-0666-x

Gotelli NJ, Graves GR (1996) Null models in ecology, Smithsonia

Guirado M, Pino J, Rodà F (2006) Understorey plant species richness and composition in metropolitan forest archipelagos: effects of forest size, adjacent land use and distance to the edge. Glob Ecol Biogeogr 15:50-62. https://doi.org/10.1111/j.1466-822X.2006. 00197.x

Guirado M, Pino J, Rodà F (2007) Comparing the role of site disturbance and landscape properties on understory species richness in fragmented periurban Mediterranean forests. Landsc Ecol 22:117129. https://doi.org/10.1007/s10980-006-9009-y

Hansen MC, Potapov PV, Moore R et al (2013) High-resolution global maps of 21st-century forest cover. Change. 850:850-854. https:// doi.org/10.1126/science. 1244693

Heilman GE, Strittholt JR, Slosser NC, DellaSala DA (2002) Forest fragmentation of the conterminous United States: assessing forest intactness through road density and spatial characteristics. BioSience 52: 411-422

Hesselbarth MHK, Sciaini M, With KA, et al (2019) Landscapemetrics : an open-source R tool to calculate landscape metrics. Ecography (Cop) 1-10. doi: https://doi.org/10.1111/ecog.04617

IGN (2019) Cartografía general del mundo y Europa del Instituto Geografico Nacional. Atlas Nac. España http://atlasnacional.ign.es

Jaeger JAG (2000) Landscape division, splitting index, and effective mesh size: new measures of landscape fragmentation. Landsc Ecol 15:115-130

Jaeger JAG, Soukup T, Schwick C et al (2016) Landscape fragmentation in Europe. Eur Landsc Dyn L Cover data:157-198

Jongman RHG (2002) Homogenisation and fragmentation of the European landscape: ecological consequences and solutions. Landsc Urban Plan 58:211-221. https://doi.org/10.1016/S01692046(01)00222-5

Kim DH, Sexton JO, Noojipady P et al (2014) Global, Landsat-based forest-cover change from 1990 to 2000. Remote Sens Environ 155:178-193. https://doi.org/10.1016/j.rse.2014.08.017

Kupfer JA (2012) Landscape ecology and biogeography: rethinking landscape metrics in a post-FRAGSTATS landscape. Prog Phys Geogr 36:400-420. https://doi.org/10.1177/0309133312439594

Liebhold AM, Brockerhoff EG, Kalisz S et al (2017) Biological invasions in forest ecosystems. Biol Invasions 19:3437-3458. https://doi.org/ 10.1007/s10530-017-1458-5

Mantyka-Pringle CS, Martin TG, Rhodes JR (2012) Interactions between climate and habitat loss effects on biodiversity: a systematic review and meta-analysis. Glob Chang Biol 18:1239-1252. https://doi.org/ 10.1111/j.1365-2486.2011.02593.x

Marull J, Otero I, Stefanescu C, Tello E, Miralles M, Coll F, Pons M, Diana GL (2015) Exploring the links between forest transition and landscape changes in the Mediterranean. Does forest recovery really 
lead to better landscape quality? Agrofor Syst 89:705-719. https:// doi.org/10.1007/s10457-015-9808-8

Mazzoleni S, di Pasquale G, Mulligan M et al (2004) Recent dynamics of the Mediterranean vegetation and landscape. John Wiley \& Sons

McGarigal K, Marks BJ (1994) FRAGSTATS: spatial pattern analysis program for quantifying landscapes structure. Gen tech rep PNWGTR-351 US Dep Agric for Serv Pacific northwest Res Station Portland, OR 97331:134. https://doi.org/10.1061/(ASCE)07339437(2005)131:1(94)CE

Melero Y, Stefanescu C, Pino J (2016) General declines in Mediterranean butterflies over the last two decades are modulated by species traits. Biol Conserv 201:336-342. https://doi.org/10.1016/j.biocon.2016. 07.029

Messier C, Bauhus J, Doyon F, Maure F, Sousa-Silva R, Nolet P, Mina M, Aquilué N, Fortin MJ, Puettmann K (2019) The functional complex network approach to foster forest resilience to global changes. For Ecosyst 6:1-16. https://doi.org/10.1186/s40663-019-0166-2

Metzger MJ, Bunce RGH, Jongman RHG et al (2005) A climatic stratification of the environment of Europe. Glob Ecol Biogeogr 14:549 563. https://doi.org/10.1111/j.1466-822X.2005.00190.x

Meyfroidt P, Lambin EF (2011) Global forest transition: prospects for an end to deforestation. Annu Rev Environ Resour 36:343-371. https:// doi.org/10.1146/annurev-environ-090710-143732

Nagendra H, Reyers B, Lavorel S (2013) Impacts of land change on biodiversity: making the link to ecosystem services. Curr Opin Environ Sustain 5:503-508. https://doi.org/10.1016/j.cosust.2013. 05.010

Otero I, Marull J, Tello E et al (2015) Land abandonment, landscape, and biodiversity: questioning the restorative character of the forest transition in the Mediterranean. Ecol Soc 20. https://doi.org/10.5751/ ES-07378-200207

Pagnutti C, Bauch CT, Anand M (2013) Outlook on a worldwide forest transition. PLoS One 8. https://doi.org/10.1371/journal.pone. 0075890

Palmero M, Espelta JM, Gordillo J, Pino J (2020) Changes in forest landscape patterns resulting from recent afforestation in Europe (1990-2012): defragmentation of pre-existing forest versus new patch proliferation. Mendeley Data, V2, https://doi.org/10.17632/ hwntrn78vc. 2

Perfecto I, Vandermeer J (2010) The agroecological matrix as alternative to the land-sparing/agriculture intensification model. Proc Natl Acad Sci U S A 107:5786-5791. https://doi.org/10.1073/pnas. 0905455107

Perlin J, Journey AF (1989) The role of wood in the development of civilization
Plieninger T, Gaertner M, Hui C, Huntsinger L (2013) Does land abandonment decrease species richness and abundance of plants and animals in Mediterranean pastures, arable lands and permanent croplands? Environ Evid:1-7

R Core Team (2012) R: a language and environment for statistical computing. R Foundation for Statistical Computing, Vienna, Austria. http://www.r-project.org/

Ramage BS, Kitzes J, Marshalek EC, Potts MD (2013) Optimized floating refugia: a new strategy for species conservation in production forest landscapes. Biodivers Conserv 22:789-801. https://doi.org/ 10.1007/s10531-013-0453-0

Regos A, Domínguez J, Gil-Tena A, Brotons L, Ninyerola M, Pons X (2016) Rural abandoned landscapes and bird assemblages: winners and losers in the rewilding of a marginal mountain area (NW Spain). Reg Environ Chang 16:199-211. https://doi.org/10.1007/s10113014-0740-7

Rudel TK, Coomes OT, Moran E et al (2005) Forest transitions: towards a global understanding of land use change. Glob Environ Chang 15: 23-31. https://doi.org/10.1016/j.gloenvcha.2004.11.001

Rudel TK, Defries R, Asner GP, Laurance WF (2009) Changing drivers of deforestation and new opportunities for conservation. Conserv Biol 23:1396-1405. https://doi.org/10.1111/j.1523-1739.2009. 01332.x

Saunders DA, Hobbs RJ, Margules CR (1999) Biological consequences of ecosystem fragmentation: a review. NCASI Tech Bull 2:469-470

Saura S, Pascual-Hortal L (2007) A new habitat availability index to integrate connectivity in landscape conservation planning: comparison with existing indices and application to a case study. Landsc Urban Plan 83:91-103. https://doi.org/10.1016/j.landurbplan.2007. 03.005

Turner MG (2005) Landscape ecology: what is the state of the science? Annu Rev Ecol Evol Syst 36:319-344. https://doi.org/10.1146/ annurev.ecolsys.36.102003.152614

Turner MG (1989) Landscape ecology: the effect of pattern on process. Annu Rev Ecol Syst Vol 20

Vellend M, Verheyen K, Flinn KM et al (2007) Homogenization of forest plant communities and weakening of species-environment relationships via agricultural land use. J Ecol 95:565-573. https://doi.org/ 10.1111/j.1365-2745.2007.01233.x

Weng YC (2007) Spatiotemporal changes of landscape pattern in response to urbanization. Landsc Urban Plan 81:341-353. https:// doi.org/10.1016/j.landurbplan.2007.01.009

Publisher's note Springer Nature remains neutral with regard to jurisdictional claims in published maps and institutional affiliations. 